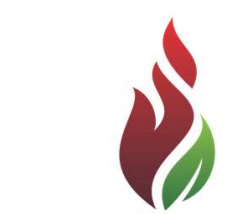

SUSTENERE

Publishing Corporation

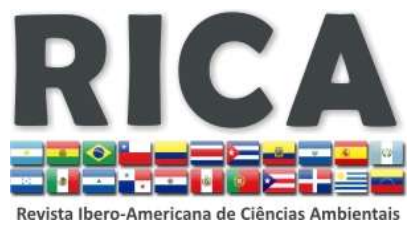

Journals Homepage:

www.sustenere.co/journals

\section{O USO DE INDICADORES NA IDENTIFICAÇÃO E GESTÃO DOS IMPACTOS CULTURAIS DO TURISMO}

\section{RESUMO}

As pesquisas sobre os impactos do turismo nas unidades de conservação focam frequentemente nos impactos ao meio biofísico e a satisfação dos visitantes. Raramente são analisadas as implicações sobre as comunidades locais. Este trabalho realizou o estudo comparativo entre duas comunidades tradicionais litorâneas: o bairro Sertão da Fazenda e a vila de Picinguaba, ambas situadas no Parque Estadual Serra do Mar, São Paulo - Brasil, com o intuito de analisar as peculiaridades dos impactos culturais da atividade turística. A metodologia proposta foi baseada no desenvolvimento de indicadores, definidos e avaliados tendo-se como parâmetro as características socioespaciais das comunidades estudadas Adotou-se como referencial teórico-metodológico, o espaço geográfico, considerando que esse exprime a relação sociedade-natureza inerente a cada cultura. Na primeira comunidade identificou-se que as práticas tradicionais se mantêm mais conservadas. Na segunda, o turismo, a consequente urbanização e fixação de segunda residência trouxeram alterações sócio-espaciais significativas. O trabalho teve ainda por objetivo avaliar a política interna do referido Parque em relação à inserção dos aspectos culturais no "Subprograma Visitação e Turismo Sustentável", buscando identificar a compatibilidade e perspectiva de aplicabilidade da presente metodologia. A pesquisa demonstrou que o uso de indicadores para a identificação dos impactos culturais do turismo é viável e sua aplicação, enquanto um instrumento de gestão, está relacionada a um processo participativo e de responsabilidade compartilhada, entre o Estado e população local, para implantação e monitoramento da atividade turística.

PALAVRAS-CHAVES: Indicadores Socioespaciais; Comunidade Tradicional; Unidade de Conservação.

\section{INDICATORS TO IDENTIFICATION AND MANAGEMENT OF TOURISM CULTURAL IMPACTS}

\section{ABSTRACT}

The research on tourism impacts in protected areas often focus on the biophysical impacts and visitor satisfaction. Rarely analyzes the implications on local communities. This work conducted a comparative study between two traditional coastal communities: the Sertão da Fazenda neighborhood and the village of Picinguaba, both located in the Serra do Mar State Park, São Paulo - Brazil, aiming to analyze the peculiarities of tourism cultural impacts. The proposed methodology was based on the development of indicators defined and evaluated taking as parameter the socio-spatial characteristics of the studied communities. The geographic space is used as a theoretical and methodological framework, considering that it can express the relationship between society and nature inherent to each culture. The traditional practices remain more conserved in the first community. In the second, tourism, urbanization and the consequent establishment of second homes brought significant socio-spatial changes. The work also aimed to evaluate the Park's internal politics, in relation to the cultural integration presented in the "Subprogram of Visitation and Sustainable Tourism", seeking to identify the compatibility and application prospect of this methodology. The research showed that the use of indicators for identifying tourism cultural impacts is viable and its application, as a management tool, is related to a participatory process and shared responsibility between the state and the local population, for implementation and monitoring of tourist activity.

KEYWORDS: Socio-Spatial Indicators; Traditional Community; Protected Area.
Revista Ibero-Americana de

Ciências Ambientais, Aquidabã,

v.6, n.1, Dez 2014, Jan, Fev, Mar, Abr, Mai 2015.

ISSN 2179-6858

\section{SECTION: Articles}

TOPIC: Ecoturismo e Conservação da Natureza

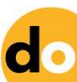

DOI: 10.6008/SPC2179-6858.2015.001.0004

Cristina de Marco Santiago

Instituto Florestal do Estado de São Paulo, Brasil http://lattes.cnpq.br/4232650628308832

cristinasantiago@if.sp.gov.br

Douglas de Souza Pimente

Universidade do Estado do Rio de Janeiro, Brasil http://lattes.cnpq.br/9374128914372886 douglasgeia@gmail.com

Giselle Natividad Cruzado Melendez Asociacion Para La Conservación Del Patrimonio de Cutivireni, Perú

http://lattes.cnpq.br/3431154300926601 chiselita@hotmail.com

Received: 04/09/2014

Approved: 14/10/2015

Reviewed anonymously in the process of blind peer.

Referencing this:

SANTIAGO, C. M.; PIMENTEL, D. S.; MELENDEZ, G. N. C. $O$ uso de indicadores na identificação e gestão dos impactos culturais do turismo. Revista Ibero-Americana de Ciências Ambientais, Aquidabã, v.6, n.1, p.40-53, 2015. DOI: http://dx.doi.org/10.6008/SPC21796858.2015 .001 .0004 


\section{INTRODUÇÃO}

Até a década de 1970 pouca atenção era dada à interação entre turistas e a comunidade local. A partir de então, profissionais e estudiosos passaram a tratar dos efeitos não econômicos induzidos por esta relação, trazendo maior consciência sobre os problemas sociais, culturais e ambientais que podem advir da atividade turística (LICKORISH \& JENKINS, 2000), passando-se a questionar as reais potencialidades do turismo como impulsor de desenvolvimento (BERTONCELLO, 1998).

De acordo com Horwich et al. (1999), o turismo de massa tem consequências negativas e de longo alcance para os povos nativos e o meio ambiente. Ele pode degradar os lugares pela visitação excessiva, provocar inflação local e salientar as diferenças culturais e econômicas entre os habitantes locais e os viajantes. Dentro deste contexto, uma nova modalidade de turismo desponta nas últimas décadas: o ecoturismo, que a princípio se diferencia do turismo de massa pela valorização das atividades junto à natureza e postura de respeito ao meio ambiente e às culturas locais (WESTERN, 1999). Por essa razão, é legalmente previsto em quase todas as categorias de manejo do Sistema Nacional de Unidades de Conservação, sendo largamente aceito como alternativa para se minimizar os conflitos com as comunidades tradicionais nas unidades de conservação (UCs) de proteção integral, conforme se observa em Terborgh e Peres (2002) e Wallace (1997), passando-se a oferecer uma possibilidade de desenvolvimento econômico compatível com o manejo dessas áreas.

Todavia, no Encontro Internacional sobre Políticas de Turismo em Parques Nacionais e outras Áreas Protegidas, em 1992, representantes da Costa Rica, Peru, República Dominicana, Equador e Venezuela reconheceram os efeitos negativos do turismo sobre as comunidades locais, as alterações, por vezes aceleradas, nas tradições e costumes: vestimenta, alimentação, linguagem, folclore, religião e atividades tradicionais de produção (FAO \& PNUMA, 1993). Apesar de haver avanços metodológicos no planejamento e monitoramento da atividade turística nas áreas protegidas (STANKEl et al., 1985; GRAEFE et al., 1990; CIFUENTES, 1992; USDI, 1997), poucos esforços foram dirigidos para o estudo do monitoramento dos impactos culturais dessas atividades. As metodologias aplicadas no manejo do uso público em unidades de conservação preveem os impactos sociais, mas sobre o ponto de vista do visitante, e não sobre a população local ou de entorno, como bem expresso nos artigos compilados por Cole (2012).

Isto é, o planejamento das atividades turísticas volta-se para os impactos negativos sobre o visitante, preocupando-se com o seu grau de satisfação e frequentemente negligencia os impactos socioculturais sobre as comunidades locais, sejam elas tradicionais ou não. Logo, o desenvolvimento de instrumentos que possibilitem o planejamento adequado e o monitoramento desses impactos é de grande importância para as áreas naturais com ocupação tradicional. Para a Organização Mundial do Turismo (WOT, 2004), o uso de indicadores de desenvolvimento sustentável são instrumentos essenciais nos processos de formulação de políticas e, nos 
processos de planejamento e de gestão dos destinos turísticos.

Apesar da escassa abordagem dos impactos socioculturais nos trabalhos sobre manejo do uso público em unidades de conservação, observa-se uma tendência de ampliação das metodologias utilizadas, as quais podem ser adaptadas para a gestão do turismo em áreas naturais protegidas também ocupadas por populações tradicionais. Watson e Wiliams (1995) citam que Landres; Cole e Watson (1994) assim como Cole (1994) expandiram a aplicação do método LAC (Limites Aceitáveis de Câmbio) que, na sua origem, respondia à necessidade de administração frente à ameaça que o uso recreacional representava à vegetação, ao solo e a experiência do visitante em ambientes silvestres. Essa expansão diz respeito à inclusão das várias características da área silvestre que necessitam de proteção e o estabelecimento de uma relação mais abrangente dos elementos que as ameaçam, incluindo-se, ainda que genericamente, a ameaça da recreação aos recursos culturais. Em um sentido mais amplo, Pimentel e Magro (2012) consideram a importância, para a gestão de parques, do entendimento do processo de inserção dessas Unidades de Conservação na realidade socioambiental das comunidades locais, sejam elas tradicionais ou não. Para tal propõem uma série de indicadores avaliativos dessa relação.

Como contribuição ao aprimoramento de metodologias de planejamento e gestão da atividade turística em áreas naturais protegidas, esse trabalho, realizado junto a duas comunidades tradicionais do Parque Estadual Serra do Mar (PESM) teve por objetivo propor e testar uma metodologia, baseada na construção de indicadores para a identificação e monitoramento de impactos socioculturais decorrentes do desenvolvimento do turismo, de modo que a proteção e valorização do patrimônio cultural seja uma variável a ser considerada. Além disso, também almejou avaliar a política interna da referida UC no que se refere à inserção dos aspectos culturais no atual Plano de Manejo - "Subprograma Visitação e Turismo Sustentável", buscando identificar a compatibilidade e perspectiva de aplicabilidade da presente metodologia.

\section{METODOLOGIA}

As comunidades tradicionais adotadas no estudo de caso: vila de Picinguaba e Sertão da Fazenda inserem-se no Núcleo Picinguaba do Parque Estadual da Serra do Mar (Figura 1), mais especificamente na Zona Histórico Cultural e Antropológica definida no Plano de Manejo dessa UC, no Município de Ubatuba. São comunidades que compartilham da cultura caiçara, sendo que a segunda diferencia-se por ser quilombola; ambas, fazendo parte do processo histórico de ocupação daquela região há várias gerações (SÃO PAULO, 2006). 


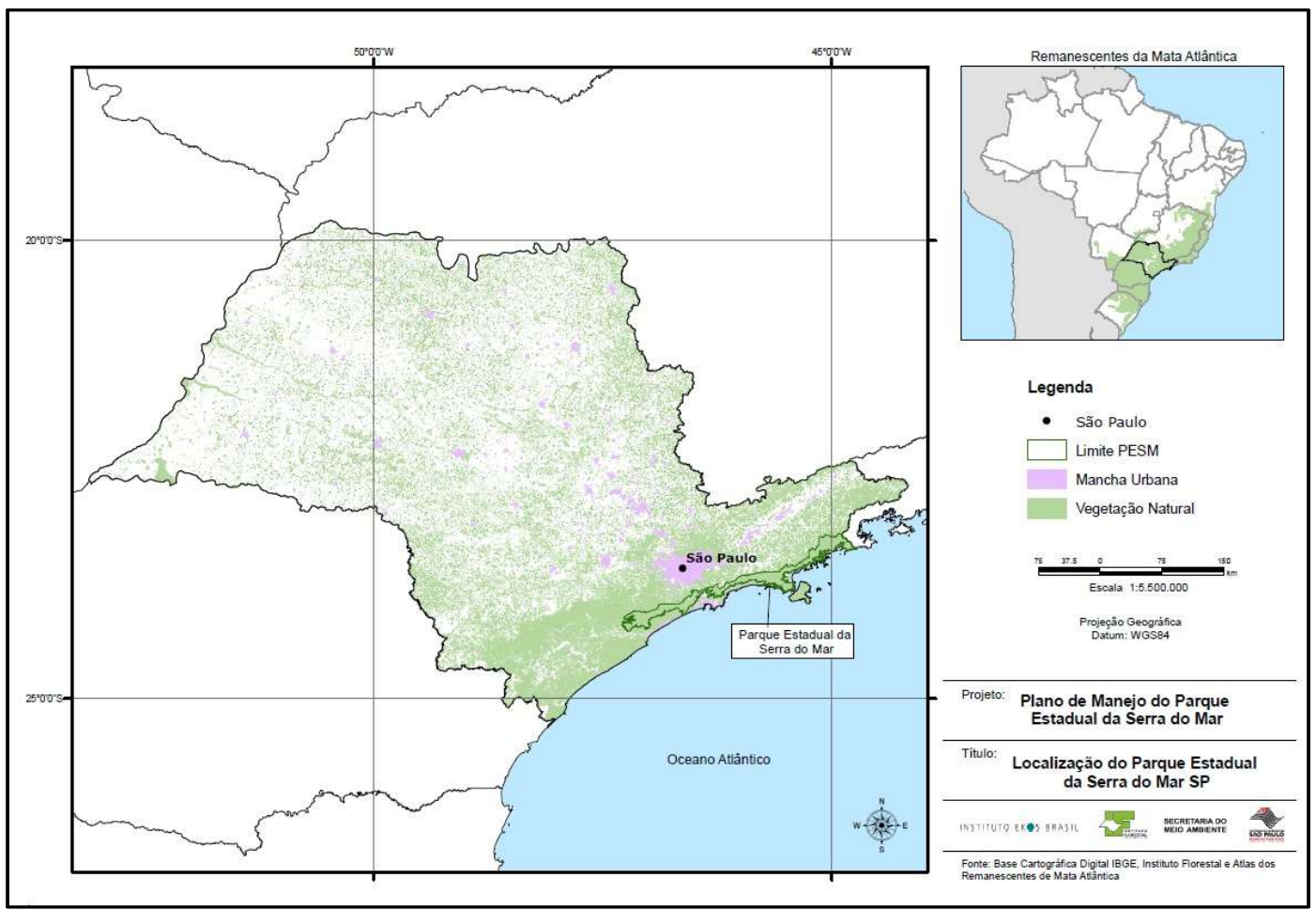

Figura 1: Mapa de localização do Parque Estadual da Serra do Mar. Demarcado em vermelho a localização aproximada das áreas de estudo no Núcleo Picinguaba, município de Ubatuba.

Fonte: Plano de Manejo do Parque Estadual da Serra do Mar (SMA, 2006).

Os indicadores de impacto e seus respectivos verificadores, bem como os parâmetros de análise foram definidos, seguindo as seguintes etapas: Levantamento bibliográfico e levantamento de parâmetros para basear a proposição de possíveis indicadores de monitoramento de impactos socioculturais do turismo (BLANGY \& WOOD, 1999; BRANDON, 1999; CEBALLOS-LASCURÁIN, 1999; COLCHESTER, 2000; COLCHESTER, 2003; FIGUEROA, 2004; HORWICH et al., 1999; KIBICHO, 2003; LINDBERG \& HUBER JUNIOR., 1999; PIRES, 2004; SIMONS, 2000; SINCLAIR, 2003). A Análise da bibliografia fundamentou a construção do Quadro 1, o qual apresenta aspectos culturais passíveis de sofrerem transformações, permitindo a definição preliminar de parâmetros de análise.

Quadro 1: Aspectos culturais passíveis de serem considerados na definição de indicadores e parâmetros de análise de impacto do turismo.

\begin{tabular}{|l|l|l|l|l|}
\hline $\begin{array}{l}\text { Relações e características } \\
\text { tradicionais dentro da } \\
\text { comunidade }\end{array}$ & \multicolumn{4}{|l|}{ Aspectos a serem monitorados } \\
\hline $\begin{array}{l}\text { Relações humanas } \\
\text { (interpessoais e grupais) }\end{array}$ & $\begin{array}{l}\text { Hierarquia e poder } \\
\text { político }\end{array}$ & $\begin{array}{l}\text { Questões de } \\
\text { gênero }\end{array}$ & $\begin{array}{l}\text { Transferência de } \\
\text { conhecimento }\end{array}$ & $\begin{array}{l}\text { Relações de } \\
\text { trabalho, sociais e } \\
\text { familiares }\end{array}$ \\
\hline Relação com a natureza & $\begin{array}{l}\text { Conhecimento sobre } \\
\text { recursos naturais e } \\
\text { seu manejo }\end{array}$ & Uso do solo & $\begin{array}{l}\text { Grau de } \\
\text { dependência dos } \\
\text { recursos naturais }\end{array}$ & $\begin{array}{l}\text { Nível de } \\
\text { interferência }\end{array}$ \\
\hline Espiritualismo & Ritos & Mitos & Simbologias & $\begin{array}{l}\text { Crenças e valores } \\
\text { morais }\end{array}$ \\
\hline Economia & $\begin{array}{l}\text { Tipo e escala das } \\
\text { atividades }\end{array}$ & $\begin{array}{l}\text { Padrões de } \\
\text { consumo }\end{array}$ & Acúmulo de capital & Divisão do trabalho \\
\hline Tecnologia & Construções & $\begin{array}{l}\text { Utensílios/ } \\
\text { artefatos e uso }\end{array}$ & Técnicas do trabalho & Equipamentos \\
\hline Linguagem & $\begin{array}{l}\text { Vocabulário, palavras } \\
\text { e expressões locais }\end{array}$ & $\begin{array}{l}\text { Domínio da } \\
\text { língua da cultura } \\
\text { dominante }\end{array}$ & $\begin{array}{l}\text { Percepções } \\
\text { expressas pela } \\
\text { linguagem }\end{array}$ & Discurso \\
\hline
\end{tabular}


Levantamento prévio sobre o processo histórico de ocupação da terra pela comunidade e das características sócio-espaciais que definem a cultura tradicional no estado de São Paulo e suas especificidades locais, realizado por meio de pesquisa bibliográfica (CANDIDO, 2003; DIEGUES, 1999; MOURA, 1978; QUEIROZ, 1973; MARCÍLIO 2006; SÃO PAULO, 1998; SÃO PAULO, 2006). Identificação de variáveis sócio-espaciais quantitativamente mensuráveis que expressam o patrimônio material e imaterial associado da comunidade em estudo - seleção dos indicadores propostos no Quadro 2.

Quadro 2: Quadro com os indicadores, verificadores de impacto sociocultural e padrões esperados para as comunidades em estudo.

\begin{tabular}{|c|c|c|}
\hline $\begin{array}{l}\text { Indicadores de } \\
\text { Impacto }\end{array}$ & Verificadores & Padrão esperado \\
\hline $\begin{array}{l}\text { Tecnologia } \\
\text { tradicional }\end{array}$ & $\begin{array}{l}\mathrm{N}^{\circ} \text { de casas que mantêm o padrão } \\
\text { construtivo tradicional } \\
\mathrm{N}^{\circ} \text { de barcos construídos com } \\
\text { técnica tradicional } \\
\mathrm{N}^{\circ} \text { de pessoas que dominam as } \\
\text { técnicas tradicionais }\end{array}$ & $\begin{array}{l}\text { Técnicas de domínio próprio: construções em taipa de mão (pau } \\
\text { a pique), canoas, confecção de utensílios e equipamentos } \\
\text { artesanais. }\end{array}$ \\
\hline Economia & $\begin{array}{l}\mathrm{N}^{\circ} \text { de pessoas na comunidade } \\
\text { trabalhando fora do âmbito } \\
\text { doméstico } \\
\mathrm{N}^{\circ} \text { de famílias que exercem as } \\
\text { atividades de plantio, de pesca e } \\
\text { de produção artesanal de } \\
\text { utensílios }\end{array}$ & $\begin{array}{l}\text { Atividades de plantio, de pesca e de extração dos recursos } \\
\text { naturais para o fabrico de equipamentos e peças diversas; mão } \\
\text { de obra familiar e ajuda vicinal; venda de excedente da } \\
\text { produção. }\end{array}$ \\
\hline Religião & $\begin{array}{l}N^{\circ} \text { de igrejas católicas e não } \\
\text { católicas }\end{array}$ & \begin{tabular}{|l|} 
Católica \\
\end{tabular} \\
\hline $\begin{array}{l}\text { Uso e } \\
\text { ocupação do } \\
\text { solo }\end{array}$ & $\begin{array}{l}\mathrm{N}^{\circ} \text { de casas ocupadas por } \\
\text { comunidades tradicionais } \\
\text { Local de ocupação dos moradores }\end{array}$ & $\begin{array}{l}\text { Organização tipicamente rural caracterizada por laços de } \\
\text { vizinhança e parentesco entre os moradores. Terra ancestral de } \\
\text { uso comunal, mantendo-se a clara noção dos limites da roça e } \\
\text { da área de moradia de cada família. }\end{array}$ \\
\hline
\end{tabular}

Estabelecimento dos padrões para os indicadores de impactos - definição das condições desejáveis/esperadas para cada indicador selecionado. Para o levantamento de dados em campo foram utilizadas entrevistas semiestruturadas e observação padronizada dos elementos em análise, conforme descritas por Triviños (1987). Adotou-se como suporte teórico-metodológico para a proposição dos indicadores, bem como para a análise dos impactos, o conceito de espaço geográfico, considerando que este exprime a relação sociedade-natureza inerente a cada cultura, a cada modo de vida (MOREIRA, 1986; MORAES, 2005; COSTA, 1988; SANTOS, 2006). Entende-se o espaço geográfico como o "conjunto, indissociável, solidário e também contraditório, de sistemas de objetos e sistemas de ações, não considerados isoladamente, mas como o quadro único no qual a história se dá" (SANTOS, 2006, p.63); onde as ações são o resultado de necessidades, naturais ou criadas - materiais, imateriais, econômicas, sociais, culturais, morais, afetivas, que conduzem à criação e ao uso de objetos pela sociedade (SANTOS, 2006). A avaliação da aplicabilidade da metodologia no contexto atual do manejo do Parque Estadual da Serra do Mar se deu por meio do método de análise documental (LÜDKE \& ANDRÉ, 1986), com base no mesmo referencial teórico; adotando-se como material de análise, o subprograma 'Visitação e Turismo Sustentável' do Plano de Manejo da referida UC (SMA, 2006). 


\section{RESULTADOS}

\section{O Impacto do Turismo sobre as Comunidades}

$\mathrm{Na}$ comunidade do Sertão da Fazenda (Figura 2) a ocupação da terra se dá pela comunidade quilombola aos moldes tradicionais. A agricultura continua sendo a atividade principal de subsistência, ocorrendo ainda, o emprego dos recursos naturais para a construção das casas, equipamentos e alguns utensílios. Cada família tem a noção exata dos limites da área que ocupa, o que já ocorria mesmo antes da demarcação exigida mais recentemente pelo INCRA. Todavia, apesar da demarcação formal, continua-se mantendo o entendimento de que a área pertence a todos. Ou seja, como é característico entre as comunidades tradicionais: a terra é comunal, mas com a clara noção dos limites da roça e da área de moradia de cada morador.

Ainda que sejam observadas algumas substituições no material empregado, prevalece o sistema construtivo em taipa de mão na edificação das casas. Mantêm-se conservadas as técnicas construtivas e a operação dos equipamentos para a produção doméstica tradicional da farinha de mandioca. São conservadas as tradições da Igreja Católica, bem como as festas religiosas tradicionais. O turismo é adotado como atividade econômica complementar. O principal impacto verificado, diz respeito à reconstrução da Casa da Farinha, que propiciou o aumento da escala de produção, permitindo aos moradores a manutenção da fabricação caseira e a comercialização do excedente. Esta prática tradicional vem sendo estimulada como de interesse turístico (aliada aos atrativos naturais da terra) e configura-se como um impacto positivo, seja reforçando a organização socioeconômica da comunidade ou a conservação de técnicas tradicionais.

A comunidade tem o entendimento de que a atividade turística pode contribuir para o seu desenvolvimento econômico. Todavia, acreditam que o sucesso do empreendimento depende da sua capacidade de organização e da manutenção cultural. Já na vila de Picinguaba, mais próxima a praia, observa-se significativas alterações nas características socioespaciais da comunidade caiçara. O local de residência original dos moradores tradicionais cedeu lugar às casas dos veranistas. Hoje a comunidade ocupa as áreas de difícil acesso, de maior declividade e nas proximidades imediatas dos córregos e nascentes. Além da degradação ambiental, observam-se situações de risco para a população, devido à possibilidade de escorregamento do terreno.

A maioria das casas dos moradores tradicionais não segue mais o padrão construtivo original, prevalece o emprego de blocos, cobertura de cimento amianto e janelas de alumínio. A ocupação original do solo, tipicamente rural, com fortes laços de vizinhança e parentesco, agora se configura urbana, caracterizando-se pela segregação social e espacial da comunidade. As atividades tradicionais como a pesca artesanal e a agricultura de subsistência estão sendo substituídas por atividades ligadas ao turismo e outras fora do âmbito da economia doméstica. Os moradores trabalham na construção civil, em órgãos públicos, em pequenas instalações comerciais, alguns são caseiros e as mulheres empregadas domésticas. 
Cerca de metade das embarcações existentes na comunidade ainda são confeccionadas em madeira, segundo a técnica tradicional, demonstrando que, embora presente, esta vem caindo em desuso. Os dados obtidos demonstram que a transmissão do saber fazer tradicional, principal suporte de reprodução cultural dessas comunidades, de uma forma geral, encontra-se severamente comprometido. Quanto à religião, observou-se que das três construções, duas correspondem à religião católica e uma à evangélica, o que configura um quadro de transformações culturais relacionadas à espiritualidade. Pode-se acrescentar a essa observação in loco, que o maior número de adeptos é da Assembleia de Deus (SÃO PAULO, 1998).

Assim, foi possível contatar que a comunidade do Sertão da Fazenda apresenta características socioculturais mais conservadas que as da comunidade da vila de Picinguaba, afetada sensivelmente pela ação da especulação imobiliária e pelo processo de urbanização que se inseriu em seu território. De acordo com os relatos dos moradores, identificou-se no Sertão da Fazenda um maior grau de conscientização quanto à especulação imobiliária. A comunidade parece ter noção clara das consequências da perda da terra, para a sua economia e sua cultura, a exemplo do que aconteceu com a vila de Picinguaba. Já nesta última, os moradores têm a percepção de que o turismo trouxe prejuízos sociais. Contudo, também atribuíram às práticas turísticas o acesso a bens de consumo que não dispunham no passado.

Desse modo, os indicadores propostos demonstraram transformações socioespaciais e, consequentemente culturais, importantes na vila de Picinguaba. Todavia, se considerarmos o turismo como um fato em si mesmo, não é possível avaliar o quanto ele foi responsável pelas mudanças observadas e até que ponto estas podem estar atrelados aos processos sociais mais amplos. Smeke et al. (2003) estudaram os impactos socioeconômicos e culturais causados pelo turismo na vila de Picinguaba, através de questionários com perguntas direcionadas a identificar a opinião dos moradores sobre o impacto do turismo em suas vidas. Dessa maneira, os autores analisaram que não houve impactos radicais e sim uma introdução gradativa do turismo nos aspectos socioeconômicos da comunidade; concluíram que os maiores impactos não foram causados pelo turismo, mas por fatores ligados à urbanização.

Segundo Luchiari (1992), a expansão da urbanização e do turismo inseriu definitivamente os caiçaras do Litoral Norte de São Paulo na economia de mercado trazendo o "progresso" do bem estar urbano, a descaracterização das áreas fisicamente preservadas e a desestabilização do equilíbrio anteriormente existente entre cultura de subsistência, atividade artesanal e ajuda mútua. $\mathrm{O}$ fato é que o turismo não está alheio à realidade dos movimentos que acontecem no mundo e não pode ser tratado como um fato em si mesmo, pois diz respeito a uma prática social que reflete, com as suas especificidades, as relações que se estabelecem na sociedade hegemônica. Como discute Cruz (2007, p.11) 'é o mundo que explica o turismo e não o contrário'.

Segundo a autora, se a produção do espaço é um processo complexo e conflituoso, entender a participação do turismo nele requer desvendar a sua natureza, sua complexidade e seus conflitos (CRUZ, 2007). Para Bertoncello (1998), os problemas relativos aos aspectos econômicos, socioculturais, ambientais e políticos trazidos pelo turismo são questões gerais da 
sociedade contemporânea que se refletem e se processam de forma específica na atividade turística. Ainda para o autor, o turismo se refere a uma série de interesses que são exógenos a sociedade local e que têm interferência direta no processo de transformação do lugar.

Os lugares povoados pelas comunidades tradicionais de cultura ainda conservada correspondem ao que Santos (2006) designa de meio geográfico natural, onde não há a produção de espaço propriamente dita, mas sim de uma nova natureza. O turismo por sua vez é uma atividade econômica que se realiza dentro da sociedade urbano-industrial contemporânea, que se desenvolve numa lógica socioespacial completamente distinta dessas comunidades. Lógica esta que, conforme o autor, produz um espaço em que a natureza deixa de ser parte significativa do meio, caracterizado por um sistema de objetos cada vez mais artificiais e um sistema de ações igualmente imbuídos de artificialidade, tendendo notadamente a fins estranhos ao lugar e a seus habitantes.

Assim, as relações sociais que passam a se desenvolver com a chegada do turismo vão desempenhar um importante papel na produção, ou reprodução, do espaço geográfico. Ao se inserir em um dado lugar, impõe as suas lógicas, provocando demandas específicas que interferem na dinâmica da sociedade que ali já estava instalada. No caso da vila de Picinguaba, observa-se que o turismo de segunda residência foi um agente desencadeador do processo de urbanização, promovendo um espaço desordenado que reflete a consequente desestruturação e segregação social da comunidade, estabelecendo-se, assim, dinâmicas vinculadas à urbanização, em que novas relações não atreladas diretamente ao turismo passaram a se estabelecer.

Como discute Yasigi (1998), a segregação induzida pelo turismo reflete a tendência geral de confinamento das cidades e espelha as distorções econômicas, sociais e culturais do país como um todo. Portanto, trata-se de um problema geral da sociedade. O processo de transformação que se observou na vila de Picinguaba é comum a várias localidades do litoral do estado de São Paulo e do Brasil e faz parte de uma racionalidade em que, conforme explica Carlos (1996), cada vez mais o espaço entra na troca, enquanto mercadoria, sendo produzido por novas indústrias como a do turismo. Muitos locais outrora ocupados por populações tradicionais, conforme observou Diegues (1996), passaram a ser adquiridos para segunda residência frente à valorização, tanto conceitual quanto econômica, do litoral brasileiro.

Os impactos do turismo, assim, estão atrelados à ascensão de um modelo de desenvolvimento social cujas implicações em relação às comunidades tradicionais foram também observadas, com suas especificidades, nas diversas regiões do estado de São Paulo, ainda nas décadas de 1950 e 1960 (CANDIDO, 2003 \& QUEIROZ, 1973), onde o turismo não foi o indutor de transformações culturais. Deve-se considerar, portanto, que os lugares estão sujeitos à influência do que ocorre na sociedade em diversos âmbitos, mas, também, que cada lugar tem suas especificidades, sua identidade, sua história, as quais vão definir as escolhas feitas e o tipo e intensidade do impacto ocorrido. Dessa perspectiva, é admissível que haja diferenças entre os resultados apresentados para as duas comunidades estudadas. Embora tão próximas uma da outra. 
É muito possível que a história de vida dos quilombolas, vinculada à formação de uma forte identidade em torno das questões relacionadas à escravidão e à luta pelo reconhecimento do seu território, tenha lhes conferido melhores condições de resistência cultural e de vínculo territorial. Outro fator que pode ter contribuído para que o bairro Sertão da Fazenda não fosse atingido pelo turismo de residência, diferentemente do que ocorreu na a vila de Picinguaba, foi a sua localização distante do mar, portanto, menos atrativa para o mercado imobiliário. O Sertão da Fazenda passou a se integrar às atividades turísticas mais recentemente, num período em que a perspectiva do ecoturismo, sob os pressupostos de valorização da natureza e da cultura local, já era dominante; em uma condição de estímulo por parte do Estado, enquanto diretriz de manejo do Parque Estadual da Serra do Mar (SÃO PAULO, 2006).

\section{As Comunidades Tradicionais e o Turismo na Perspectiva do Plano de Manejo do Parque Estadual da Serra do Mar}

A atividade turística no âmbito do Plano de Manejo do Parque Estadual da Serra do Mar é tratada no subprograma "Visitação e Turismo Sustentável", constando entre seus objetivos: "ordenar, orientar, direcionar, estruturar e monitorar a visitação, para os diferentes tipos de público, a fim de valorizar o patrimônio natural e cultural da unidade e incentivar sua conservação" (SMA, 2006, p.367). Para a consecução dos objetivos estão previstos temas de concentração estratégica com respectivos indicadores e linhas de ação.

Todavia, embora explícita a preocupação com a proteção e valorização dos aspectos culturais (do mesmo modo que em relação aos atributos naturais da UC), não foram previstas ações ou indicadores compatíveis com a gestão dos impactos culturais do turismo nos temas de concentração estratégica que poderiam tratar desta questão no referido subprograma: 'Manejo da Visitação' e 'Relação com a comunidade local'. No tema 'Manejo da Visitação' evidencia-se a preocupação somente com os impactos causados pela visitação em relação aos aspectos biofísicos: trilhas e atrativos, não havendo referência específica sobre possíveis impactos culturais às comunidades tradicionais. Aspecto que obedece à tendência geral da gestão do uso público nas UCs, conforme mencionado anteriormente.

O Tema de Concentração 'Relação com a comunidade local', apesar de contemplar claramente as comunidades tradicionais e considerar elementos importantes, carece igualmente de diretrizes, ações e indicadores voltados ao planejamento e ao monitoramento dos impactos culturais. Conforme é possível observar no Quadro 3, que sintetiza o conteúdo para este Tema, verifica-se ainda que o Subprograma, não apresenta uma perspectiva de gestão participativa do turismo em relação às comunidades tradicionais como um todo, postura que favoreceria a reflexão coletiva e talvez a minimização dos impactos.

Quadro 3: Conteúdo do Plano de Manejo do Parque Estadual da Serra do Mar, relativos às comunidades tradicionais, no tema de concentração estratégica 'Relação com a comunidade'. 


\begin{tabular}{|c|c|c|}
\hline Objetivo & Indicadores & Linhas de ação \\
\hline $\begin{array}{l}\text { Apoiar e incentivar as atividades } \\
\text { relacionadas ao turismo que possam ser } \\
\text { desenvolvidas em parceria com a } \\
\text { comunidade local. }\end{array}$ & $\begin{array}{l}\text { - Comunidade local tem uma } \\
\text { percepção positiva sobre o } \\
\text { turismo. } \\
\text { - Número (e qualidade) de } \\
\text { projetos de ecoturismo com } \\
\text { envolvimento da comunidade } \\
\text { local. } \\
\text { - Número de moradores do } \\
\text { interior ou entorno envolvidos } \\
\text { com atividades. }\end{array}$ & $\begin{array}{l}\text { - Implementar sistemas de certificação } \\
\text { e supervisão. } \\
\text { - Assegurar que só monitores } \\
\text { credenciados possam prestar serviços } \\
\text { de monitoria no Parque. } \\
\text { - Fomentar a cooperação entre } \\
\text { agências de turismo e associações de } \\
\text { monitores. } \\
\text { - Inserir os monitores ambientais no } \\
\text { planejamento e execução das } \\
\text { atividades de educação ambiental e } \\
\text { ecoturismo. } \\
\text { - Promover a capacitação e incentivar } \\
\text { a associação dos monitores ambientais } \\
\text { e demais operadores. }\end{array}$ \\
\hline
\end{tabular}

Nesse contexto, é importante destacar que a modalidade de turismo prevista nas Unidades de Conservação da Natureza é o ecoturismo. Desse modo, além da tendência geral de não se dar a devida atenção aos impactos culturais nessas áreas, soma-se o fato de que o ecoturismo, pela sua simples definição, carrega um discurso alienado que por si só parece representar a solução para todos os problemas sociais e ambientais do lugar em que ele pretende se desenvolver. Logo, assume contornos retóricos, de fácil aceitação, dificultando frequentemente a reflexão crítica durante o planejamento e aplicabilidade prática dos preceitos previstos em sua conceituação.

Portanto, cabe insistir que o turismo, em todas as suas modalidades, inclusive o ecoturismo, é antes de tudo, parte da lógica urbano-industrial contemporânea, enquanto atividade econômica e enquanto prática social e, portanto, os lugares em que ele se desenvolve estão sujeitos às determinações impostas por esta lógica. Ainda é preciso ter em mente em relação à implantação e aos impactos negativos da prática turística, conforme destaca Balastreri Rodrigues (2006), que quanto mais consolidado estiver o quadro de vida da população local e mais fortes forem as territorialidades estabelecidas sobre vínculos identitários historicamente determinados, mais complexos vão ser os embates e ajustes dentro da comunidade. Neste sentido, o Sertão da Fazenda, com suas características culturais significativamente preservadas em relação à Vila de Picinguaba, deve receber atenção especial quanto à gestão da prática turística.

Além disso, para se obter os benefícios sociais, econômicos e ambientais, advindos do turismo em áreas naturais, e para minimizar ou prevenir os impactos negativos da atividade, são necessários mecanismos participativos de planejamento que permitam às populações definir o uso de suas áreas e até mesmo optarem, se assim o julgarem, pela não adoção da prática do turismo (WOT, 2002). Nesse sentido, os indicadores de impactos socioculturais apresentam-se como importantes ferramentas de planejamento e tomada de decisão em relação às práticas turísticas. E o papel do Estado, por meio da definição de diretrizes e promoção de ações, é fundamental para que se consiga atingir os benefícios do ecoturismo de valorização e manutenção da cultura local.

Salvati (2004) cita o uso de indicadores como mecanismos de monitoramento e avaliação dos impactos positivos ou negativos do turismo, na organização social e na cultura das populações locais, no meio ambiente e na economia, possibilitando avaliar tanto o processo de 
desenvolvimento participativo do turismo quanto à sustentabilidade da atividade. Acrescenta, ainda, que os indicadores devem ser fáceis de manipular, de forma a serem entendidos e aceitos por todos os interessados, bem como devem possuir uma forma simples de verificação, por meio de parâmetros conhecidos e de fácil obtenção de dados. Assim, a metodologia proposta traz referências importantes de análise e reflexão crítica sobre os padrões socioculturais inerentes às comunidades tradicionais, essenciais na avaliação dos impactos do turismo e basilares para orientar o desenvolvimento social e econômico destas comunidades, respeitando-se seu modo de vida. Todavia, os indicadores e verificadores utilizados na análise, embora tenham sido suficientes para identificar as transformações ocorridas nas comunidades, não esgotam as diversas combinações e possibilidades presentes na mesma metodologia, podendo e devendo ser aperfeiçoados num processo participativo de planejamento.

Também, sozinhos esses indicadores não são suficientes para avaliar a gestão adequada da atividade turística propriamente dita, sendo igualmente importante medir aspectos relacionados ao nível de aceitação/satisfação da comunidade e ao comportamento e satisfação do visitante aspectos estes que incorporados ao procedimento de análise, podem orientar ações de curto e médio prazo que fortaleçam a comunidade num processo mais amplo de gestão local e, consequentemente, contribuir para a proteção do patrimônio cultural (material e imaterial).

Desse modo, é importante rever e aprimorar o subprograma 'Visitação e Turismo Sustentável' do Parque Estadual da Serra do Mar, suas diretrizes, objetivos, linhas de ação e indicadores. A implantação da atividade turística junto às comunidades tradicionais requer, necessariamente, um programa de monitoramento dos impactos culturais.

$\mathrm{O}$ processo de planejamento, avaliação e monitoramento (e consequentemente a construção de indicadores) deve basear-se na compreensão da relação sociedade-natureza destas comunidades, no diagnóstico da situação socioeconômica atual, no estudo da condição passada e na determinação do cenário futuro desejável, segundo as expectativas das populações locais. Como expõe Balastreri Rodrigues (2006, p.302), “o que está em jogo são os pontos de vista que os sujeitos sociais possuem do território, a partir da posição que nele ocupam, e das posições de conservação ou mudanças resultantes dos seus embates" em relação à prática turística. Para cada comunidade devem ser definidos, previamente, os objetivos e princípios do turismo, identificadas as possibilidades de ameaças da atividade para o patrimônio cultural e ambiental local, bem como estabelecidas as metas e os indicadores de impacto.

Os indicadores terão sua aplicabilidade real na gestão adequada do turismo, se forem construídos e avaliados periodicamente de forma participativa, permitindo que o Poder Público e a comunidade atuem preventivamente e corretivamente sobre os efeitos indesejados à cultura local. $O$ delineamento de um conjunto de indicadores e verificadores que reflitam os padrões culturais e as especificidades de cada local, bem como uma análise crítica que considere a lógica em que se insere a prática turística pode estabelecer uma política socioambiental mais ampla, possibilitando que os erros do passado sejam evitados. 


\section{CONCLUSÕES}

Potencialmente, o turismo tanto pode ser um veículo para promover o desenvolvimento local, por meio da valorização do patrimônio ambiental e cultural, como também pode ser um indutor de transformações indesejáveis afetando drasticamente a estrutura social do lugar e submetendo o espaço à degradação, em função dos seus interesses. Apesar de o ecoturismo ter como princípio a valorização e uso sustentável do patrimônio natural e cultural, bem como o envolvimento e retorno de benefícios socioeconômicos à população local, ele possui os mesmos pressupostos que qualquer outra modalidade de turismo para a sua realização: a implantação de toda gama, necessária de infraestruturas de serviços e de transporte para atender o turista consumidor. Portanto, configura-se como uma atividade econômica que se realiza dentro da sociedade urbano-industrial contemporânea, a qual se desenvolve numa lógica socioespacial totalmente distinta das comunidades tradicionais que, em geral, ocupam as áreas de interesse para o desenvolvimento desta prática.

Os indicadores e verificadores testados na presente pesquisa, no conjunto, possibilitaram identificar transformações culturais ocorridas nas duas comunidades caiçaras estudadas, ficando evidenciado o quão podem ser úteis ao monitoramento dos impactos socioculturais em projetos e ações de desenvolvimento. Os quadros apresentados na metodologia reúnem diferentes possibilidades de indicadores que podem servir de base para outros estudos, bem como contribuir para o aprimoramento da política de desenvolvimento do turismo que hoje incide sobre as comunidades estudadas. Todavia, os indicadores culturais serão ferramentas de análise e avaliação que exercerão o seu papel de instrumentar a gestão do turismo de forma a minimizar os seus impactos negativos e potencializar os positivos (não apenas prestando-se a estudos de simples identificação desses), caso haja um processo participativo de planejamento, gestão e tomada de decisão. Ou seja, um processo em que a comunidade tenha possibilidade de escolher de forma consciente, adotar ou não o turismo enquanto prática econômica, tendo a clareza dos seus riscos e possibilidades em sua organização socioespacial. Assim, o programa de monitoramento deve instrumentar a intervenção da própria comunidade e do poder público, de maneira que a atividade turística se implante ou, seja redirecionada, para garantir a valorização da cultura tradicional e a proteção do patrimônio natural.

\section{REFERÊNCIAS}

BALASTRERI RODRIGUES, A.. Turismo e territorialidades plurais: lógicas excludentes ou solidariedade organizacional. San Pablo: Consejo Latinoamericano de Ciencias Sociales, 2006.

BERTONCELLO, R.. Las prácticas turísticas y sus implicancias socio espaciales. Fortaleza: UECE, 1998.

CRUZ, R. C. A.. A produção do espaço: ponto de partida e de chegada. São Paulo: Roca, 2007.

BLANGY, S. \& WOOD, M. E.. Desenvolvendo e implementando diretrizes ecoturísticas para áreas naturais e comunidades vizinhas. São Paulo: Editora SENAC, 1999. 
BOO, E.. Planejamento ecoturístico para áreas protegidas. São Paulo: Editora SENAC, 1999.

BRANDON, K.. Etapas básicas para incentivar a população local em projetos de turismo de natureza. São Paulo: Editora SENAC, 1999.

CANDIDO, A.. Os Parceiros do Rio Bonito: Estudo sobre o caipira paulista e a transformação dos seus meios de vida. 10 ed. São Paulo: Livraria Duas Cidades, 2003.

CARLOS, A. F.. O lugar no/do mundo. São Paulo: Hucitec, 1996.

CEBALLOS-LASCURÁIN, H.. O ecoturismo como fenômeno mundial. São Paulo: Editora SENAC, 1999.

CIFUENTES, M.. Determinación de la capacidad de carga turística en áreas protegidas. Turriaba: Centro Agronómico Tropical de Investigación y Enseñanza, CATIE, Costa Rica, 1992.

COLCHESTER, M.. Resgatando a natureza: comunidades tradicionais e áreas protegidas. São Paulo: HUCTEC, NUPAUB - USP, 2000.

COLCHESTER, M.. Naturaleza Cercada: Pueblos Indígenas, áreas protegidas y conservación de la biodiversidad. Uruguay. Montevideo: Movimiento Mundial por los Bosques Tropicales, 2003.

COLE, D. N.. Wilderness visitor experiences: Progress in research and management. Fort Collins: Department of Agriculture, Forest Service, Rocky Mountain Research Station, 2012.

COSTA, W. M. D.. O Estado e as políticas territoriais no Brasil. 9 ed. São Paulo: Contexto, 1988.

DIEGUES, A. C. S; NOGARA, P. J.. O nosso lugar virou parque: estudo sócio-ambiental do saco de Mamaguá, Parati - Rio de Janeiro. 2 ed. São Paulo: NUPAUB, USP, 1999.

FIGUEROA V. E.. La relación entre pueblo Indígena y comunidad. Buenos Aires: Facultad de Derecho Universidad de Buenos Aires, 2004.

GRAEFE, A. R.; KUSS F. R.; VASKE, J. J.. Visitor impact management: The planning framework. Washington: National Parks and Conservation association, 1990

HORWICH R. H.; MURRAY, D.; SAQUI, E.; LYON, J.; GODFREY, D.. O ecoturismo e o desenvolvimento da comunidade: a experiência de Belize. São Paulo: Editora SENAC, 1999.

$\mathrm{KIBICHO}, \mathrm{W}$.. Community tourism: a lesson from Kenya's coastal region. Journal of Vacation Marketing. London, v. 10, n.1, p.33-43, 2003

LICKORISH, L. J.; JENKINS C. L.. Aspectos culturais e sociais do turismo. Rio de Janeiro: Campus, 2000.

LINDBERG, K.; HUBER JUNIOR, R. M.. Questões econômicas na gestão do ecoturismo. São Paulo. São Paulo: SENAC, 1999.

LUCHIARI, M. T. D. P.. Caiçaras, Migrantes e turistas: a Trajetória da Apropriação da Natureza no Litoral Norte Paulista (São Sebastião - Distrito de Maresias). Dissertação (Mestrado em Sociologia) - Instituto de Filosofia e Ciências Humanas da UNICAMP, Campinas, 1992.

LÜDKE, M.; ANDRE, M. E. D. A.. Pesquisa em educação: abordagens qualitativas. São Paulo: Editora Pedagógica Universitária Ltda, 1986.

MARCÍLIO, M. L.. Caiçara, terra e população: estudo de demografia histórica e da história social de Ubatuba. 2 ed. São Paulo: Edusp, 2006.

MORAES, A. C. R.. Ideologias geográficas. 5 ed. São Paulo: Hucite, 2005.

MOREIRA, R.. O que é geografia. 7 ed. São Paulo: Editora Brasiliense, 1986.

MOURA, M. M.. Os Herdeiros da terra: parentesco e herança nua área rural. São Paulo: Editora Hucitec, 1978. 
ORGANIZACIÓN DE LAS NACIONES UNIDAS PARA LA AGRICULTURA Y LA ALIMENTACIÓN \& PROGRAMA DE LAS NACIONES UNIDAS PARA EL MEDIO AMBIENTE - FAO/PNUMA. EI turismo en los parques nacionales y otras áreas protegidas de América Latina. Santiago, Chile: Oficina Regional de la FAO para América Latina y el Caribe, 1993. (Documento Técnico, $n^{\circ} 11$ )

PIMENTEL, D.S.; MAGRO, T. C.. Indicadores para a gestão da inserção social de parques. OLAM Ciência e Tecnologia, Rio Claro, v. 12, n.1-2, p.254-277, 2012.

PIRES, E. V.. Impactos sócio-culturais do turismo sobre as Comunidades Receptoras: Uma Análise Conceitual. Caderno Virtual de Turismo, Rio de Janeiro, v.4, n.3, p1-8, 2004.

QUEIROZ, M. I. P. D.. Bairros rurais paulistas: dinâmica das relações bairro rural - cidade. São Paulo: Livraria duas cidades, 1973.

SALVATI, S. S..Turismo responsável: manual para políticas Locais. Programa de Turismo e Meio Ambiente. Brasília: WWF-Brasil, 2004.

SANTOS, M.. A natureza do espaço: técnica e tempo, razão e emoção. 4 ed. São Paulo: Hucitec, 2006.

SÃO PAULO (ESTADO). SECRETARIA DO MEIO AMBIENTE. Resolução n 28, de 28 de março de 1998. Publica e implementa os Planos de Gestão de 11 (onze) Unidades de Conservação sob a administração da Secretaria do Meio Ambiente. São Paulo, 28 mar 1998.

SÃO PAUlO (ESTADO). SECRETARIA DO MEIO AMBIENTE. Plano de Manejo do Parque Estadual da Serra do Mar. São Paulo: Instituto Florestal, 2006.

SIMONS, M. S.. Aboriginal heritage art and moral rights. Annals of Tourism Research, Sydney, v.27, n.2, p.412-431, 2000.

SMEKE, I. M.; MORAES DE C, C.; MARTOS H, L.. Impactos socioeconômicos e culturais causados pelo turismo na comunidade da Vila Picinguaba, em Ubatuba - SP. Trabalho de Conclusão de Curso. (Graduação em Turismo) - Pontifícia Universidade Católica de Campinas, Campinas, 2013.

STANKEY, G. H.; COLE, D. N. ; LUCAS, R. C. PETERSEN, M. E.; FRISSELL. S. S..The limits of acceptable change (LAC) system for wilderness planning. Ogden: United States Department of Agriculture, 1985.

TERBORGH, J.; PERES, C. A.. O problema das pessoas nos parque. Curitiba: Fundação O Boticário, 2002.

TRIVINÕS, A. N. S.. Introdução à pesquisa em ciências sociais: a pesquisa qualitativa em educação. 4 ed. São Paulo: Atlas, 1995.

UNITED STATES. DEPARTMENT OF THE INTERIOR / NATIONAL PARK SERVICE (USDI). A summary of the visitors experience and resource protection (VERP) framework. Denver: NPS Denver Service Center, 1997.

WALLACE G. N.. (1997) Turismo ecológico en unidades de conservación: ¿ Cual es el limite? In: CONGRESSO BRASILEIRO DE UNIDADES DE CONSERVAÇÃO. 1. Anais. Curitiba: UFP, 1997.

WATSON A. E.; WILLIAMS D. R.. Priority for human Experience Research in wilderness.

Trends/Wilderness Research, v.32, n.1, p.14-18, 1995.

WESTERN, D.. Prefácio: definindo ecoturismo. São Paulo: SENAC, 1999.

YÁZIGI, E.. Turismo, uma esperança condicional. São Paulo: Plêiade, 1998. 